\title{
Ionosphere dynamics over Europe and western Asia during magnetospheric substorms 1998-99
}

\author{
D. V. Blagoveshchensky ${ }^{1}$, O. A. Maltseva ${ }^{2}$, and A. S. Rodger ${ }^{3}$ \\ ${ }^{1}$ University of Aerospace Instrumentation, St. Petersburg, 190000, Russia \\ ${ }^{2}$ Institute of Physics, Rostov University, Rostov-on-Don, 344090, Russia \\ ${ }^{3}$ British Antarctic Survey, Madingley Road, Cambridge, CB3 OET, UK
}

Received: 17 October 2001 - Revised: 5 September 2002 - Accepted: 24 October 2002

\begin{abstract}
The temporal and spatial behaviour of the ionospheric parameters $f o \mathrm{~F} 2$ and $h^{\prime} \mathrm{F}$ during isolated substorms are examined using data from ionospheric stations distributed across Europe and western Asia. The main purpose is finding the forerunners of the substorm disturbances and a possible prediction of these disturbances. During the period from March 1998 to March 1999, 41 isolated substorms with intensities $I=60-400 \mathrm{nT}$ were identified and studied. The study separated occasions when the local magnetometers were affected by the eastward electrojet (positive substorms) from those influenced by the westward electrojet (negative substorms). The deviations of the ionospheric parameters from their monthly medians $\left(\Delta f o \mathrm{~F} 2\right.$ and $\left.\Delta h^{\prime} \mathrm{F}\right)$ have been used to determine the variations through the substorm. Substorm effects occurred simultaneously $(<1 \mathrm{~h})$ across the entire observatory network. For negative substorms, $\Delta f o \mathrm{~F} 2-$ values increase $>6 \mathrm{~h}$ before substorm onset, $T_{o}$, reaching a maximum $2-3 \mathrm{~h}$ before $T_{0}$. A second maximum occurs $1-2 \mathrm{~h}$ after the end of the substorm. The $\Delta h^{\prime} \mathrm{F}$ values $3-4 \mathrm{~h}$ before $T_{o}$ have a small minimum but then increase to a maximum at $T_{o}$. There is a second maximum at the end of the expansion phase before $\delta h^{\prime} \mathrm{F}$ drops to a minimum $2-3 \mathrm{~h}$ after ending the expansion phase. For positive substorms, the timing of the first maximum of the $\delta f o \mathrm{~F} 2$ and $\delta h^{\prime} \mathrm{F}$ values depends on the substorm length - if it is longer, the position is closer to $T_{o}$. The effects on the ionosphere are significant: $\Delta f o \mathrm{~F} 2$ and $\Delta h^{\prime} \mathrm{F}$ reach $2-3 \mathrm{MHz}(\delta f o \mathrm{~F} 2=50-70 \%$ from median value) and $50-70 \mathrm{~km}\left(\delta h^{\prime} \mathrm{F}=20-30 \%\right.$ from median value), respectively. Regular patterns of occurrence ahead of the first substorm signature on the magnetometer offer an excellent possibility to improve short-term forecasting of radio wave propagation conditions.
\end{abstract}

Key words. Ionosphere (ionospheric disturbances) - Magnetospheric physics (storms and substorms) Radio science (ionospheric physics)

\section{Introduction}

Reconnection at the dayside magnetopause results in open flux being transported into the geomagnetic tail. When there is a significant accumulation of open flux, instability occurs and there is major reconfiguration of the tail. The latter part of the cycle is known as the substorm that begins at 6-10 $R_{E}$ (Lui, 1991). It is preceded by a growth phase, which can last $\sim 1-2 \mathrm{~h}$. A dramatic brightening of the aurora, the establishment of the substorm current wedge and a Pi2 pulsation mark the beginning of the expansion phase. The third and final element of the substorm is the recovery phase that begins after the maximum deviation of the magnetometers near midnight in the auroral oval. Despite the substorm being described first nearly 40 years ago (Akasofu, 1968), detailed understanding of the physical processes and their ionospheric consequences are not well understood. This is certainly due in part to the fact that no two substorms are identical, and many substorms are actually the superposition of several expansion phases, making interpretation complex.

Early in the papers (Blagoveshchensky et al., 1992, 1996; Blagoveshchensky and Borisova, 2000) the effect of the maximum useable frequency (MUF) variations on the HF radio paths during substorms was revealed. Effect essence is increasing the MUF values some hours before the moment $T_{o}$, decreasing those during the substorm expansive phase and increasing the MUF values again within some hours during the recovery phase. The purpose of this paper is to examine the temporal and spatial behaviour of $f o \mathrm{~F} 2$, the maximum plasma frequency of the F2-layer, and $h^{\prime} \mathrm{F}$, the virtual height of the Flayer (Piggott and Rawer, 1978), during isolated substorm intervals, to identity consistent features that could be used for ionospheric modelling and for radio-wave propagation calculations. Special attention will be given to the ionospheric parameter behaviour before substorm.

\section{Data used and substorm parameters}

Hourly values of $f o \mathrm{~F} 2$ and $h^{\prime} \mathrm{F}$ derived from ionosonde data from Ionospheric Despatch Centre in Europe (IDCE) (Stanislavska el al., 1998) and some Finnish observatories 
Table 1. Parameters of substorms by Sodankyla observatory

\begin{tabular}{|c|c|c|c|c|c|c|}
\hline \multirow[t]{2}{*}{ Date } & \multirow{2}{*}{$\begin{array}{c}\text { Substorm } \\
\text { onset, } T_{o}(\mathrm{UT})\end{array}$} & \multirow[t]{2}{*}{ Intensity $I(\mathrm{nT})$} & \multirow[t]{2}{*}{ Duration $\tau(\mathrm{h})$} & \multicolumn{3}{|c|}{ Absorption } \\
\hline & & & & SOD & OUL & JYV \\
\hline $17-18.03 .98$ & 22 & -160 & 3 & 0,9 & 0,2 & 0 \\
\hline 09-10.04.98 & 20 & -200 & 5 & 0,2 & 0,1 & 0 \\
\hline $14-15.04 .98$ & 15 & +80 & 3,5 & 1 & 0,3 & 0 \\
\hline 17.04 .98 & 13 & +250 & 3 & 0,2 & 0,05 & 0 \\
\hline 19-20.04.98 & 20 & -120 & 2,5 & 0,15 & 0 & 0 \\
\hline 20.04 .98 & 13 & +300 & 2 & 0,9 & 0,6 & 0 \\
\hline $28-29.04 .98$ & 20 & -100 & 2,5 & 0,2 & 0 & 0 \\
\hline $29-30.04 .98$ & 21 & -100 & 2 & 0,2 & 0 & 0 \\
\hline $15-16.05 .98$ & 21 & -140 & 1,5 & 0,4 & - & 0 \\
\hline $16-17.05 .98$ & 20 & -180 & 2 & 1,1 & - & 0 \\
\hline $24-25.05 .98$ & 20 & -160 & 3 & 0,4 & - & 0 \\
\hline 02-03.06.98 & 23 & -100 & 1 & 0,3 & 0,02 & 0,01 \\
\hline 10.06 .98 & 12 & +200 & 3 & 0,3 & 0,01 & - \\
\hline $10-11.06 .98$ & 23 & -400 & 4 & 1,9 & 0,05 & 0,03 \\
\hline $13-14.06 .98$ & 23 & -210 & 2 & 0,4 & 0 & 0 \\
\hline 15.06 .98 & 12 & +150 & 5,5 & 0,15 & 0,2 & 0,5 \\
\hline $16-17.06 .98$ & 14 & +190 & 3 & 0,4 & 0,2 & 0,35 \\
\hline $01-02.07 .98$ & 23 & -270 & 2,5 & 1,4 & 0,3 & 0,4 \\
\hline 03-04.07.98 & 22 & -380 & 3,5 & 1,5 & 0,2 & 0 \\
\hline $18-19.07 .98$ & 21 & -180 & 2 & 0,4 & - & - \\
\hline $28-29.07 .98$ & 21 & -200 & 6 & 1 & 0,2 & 0 \\
\hline 10.08 .98 & 02 & -120 & 2 & 1,5 & 0,3 & - \\
\hline $11-12.08 .98$ & 23 & -400 & 2,5 & 0,7 & 0,01 & - \\
\hline $12-13.08 .98$ & 23 & -300 & 2 & 1,8 & 0,2 & - \\
\hline $14-15.09 .98$ & 21 & -250 & 1 & 0,4 & 0 & - \\
\hline $15-16.09 .98$ & 14 & +70 & 5 & 0 & 0 & 0 \\
\hline $22-23.09 .98$ & 20 & -180 & 2 & 0,3 & 0 & 0,1 \\
\hline $28-29.09 .98$ & 20 & -150 & 1,5 & 0,25 & 0 & - \\
\hline 29-30.09.98 & 20 & -350 & 1,5 & 1,7 & 0,2 & - \\
\hline 06-07.10.98 & 23 & -190 & 2 & 0,8 & 0,2 & - \\
\hline 20-21.02.99 & 20 & -90 & 2 & 0,15 & 0 & 0 \\
\hline $23-24.02 .99$ & 17 & +220 & 1 & 0,2 & 0,15 & 0 \\
\hline 25.02 .99 & 04 & -60 & 2 & 0,8 & 0,2 & 0 \\
\hline 25.02 .99 & 16 & +60 & 1,5 & 0,1 & 0,05 & 0 \\
\hline 27-28.02.99 & 20 & -80 & 1,5 & 0,1 & 0 & 0 \\
\hline 05-06.03.99 & 16 & +220 & 1,5 & 0 & 0 & 0 \\
\hline 13.03 .99 & 12 & +90 & 3 & 0,2 & 0,2 & 0,2 \\
\hline 20-21.03.99 & 17 & +130 & 3,5 & 0,7 & 0 & 0,1 \\
\hline $23-24.03 .99$ & 21 & -90 & 2 & 0,2 & 0 & 0 \\
\hline $25-26.03 .99$ & 19 & -400 & 4 & 0,7 & 0,2 & 0 \\
\hline 27-28.03.99 & 22 & -110 & 1,5 & 0,8 & 0,15 & 0 \\
\hline
\end{tabular}

are used. The former includes data from 19 stations in Europe and from western Asia.

The northward $(X)$ components of the magnetic field from Sodankyla $\left(67.4^{\circ} \mathrm{N}\right)$, Oulujarvi $\left(64.5^{\circ} \mathrm{N}\right)$, Hankasalmi $\left(62.3^{\circ} \mathrm{N}\right)$ and Nurmijarvi $\left(60.5^{\circ} \mathrm{N}\right)$ are used to determine the onset time of the expansion phase, $T_{o}$, determined to an accuracy of $0.25 \mathrm{~h}$. Isolated substorms are those where no other substorm has been identified for $>6 \mathrm{~h}$ prior to, or following the one selected. The identification of the substorm was checked by examining other data sets. These included preliminary $A E$-indices from the Kyoto WDC-C2, $P C$-indexes from Thule and Vostok stations (Troshichev et al., 1988), and riometer data from Sodankyla $(f=30 \mathrm{MHz})$, Oulujarvi $(f=30 \mathrm{MHz})$ and Jyvaskyla $(f=32.4 \mathrm{MHz})$. During the interval March 1998 to March 1999, 41 isolated substorms of moderate intensity were identified. Their intensity, $I$, varied between $60-400 \mathrm{nT}$, where $I$ is the magnetic field value in the maximum of bay. There were 12 positive and 29 negative substorms. Positive and negative indicate when the magnetic observatories were under the influence of the eastward and westward electrojet, respectively. The duration of the substorm is defined as the time between $T_{o}$ and $T_{e}$, the time 

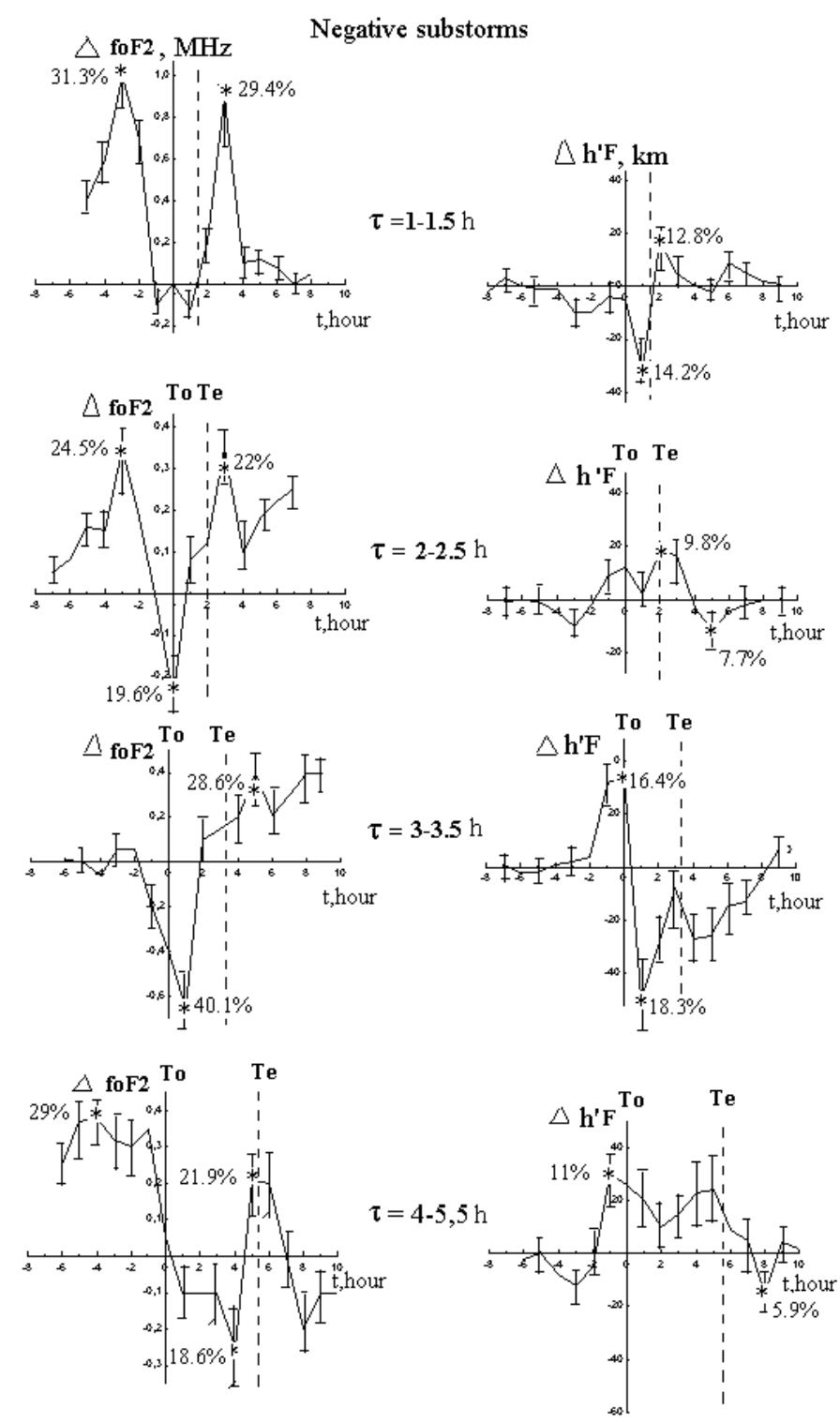

Fig. 1. The average variations of $\Delta f o \mathrm{~F} 2$ and $\Delta h^{\prime} \mathrm{F}$ separated by duration into 4 classes: $\tau=1-1.5 \mathrm{~h}, \tau=2-2.5 \mathrm{~h}, \tau=3-3.5 \mathrm{~h}$, and $\tau=4-6 \mathrm{~h}$. The vertical lines mark substorm onset, $T_{o}$, and the average end of the substorm. $T_{e}$. Asterisks are $\delta f o \mathrm{~F} 2(\%)$ and $\delta h^{\prime} \mathrm{F}(\%)$ values.

when the magnetic disturbance level has returned to the presubstorm level. The $T_{o}$ values and duration of the substorm expansion phase are listed in Table 1. Key findings from the table are:

- For positive substorms, $T_{o}$ occurs uniformly between 12:00 UT and 17:00 UT.

- For negative substorms, $T_{o}$ values occur over a wider interval (19:00-04:00 UT), but the probability distribution has two maxima, at 20:00 UT (Probability $P=$ $0.35)$ and 23:00 UT $(P=0.25)$.

- The duration of the expansion phase of positive substorms $(\tau)$ ranges between 1 and $5.5 \mathrm{~h}$, and $1-6 \mathrm{~h}$ for negative substorms.
- The values of $\Delta f o \mathrm{~F} 2$ and $\Delta h^{\prime} \mathrm{F}$ during a substorm can reach the sizes $|\Delta f o \mathrm{~F} 2|=2-3 \mathrm{MHz}$ (i.e. $\delta f o \mathrm{~F} 2=50$ $70 \%$ from median value) and $\left|\Delta h^{\prime} \mathrm{F}\right|=50-70 \mathrm{~km}$ (i.e. $\delta h^{\prime} \mathrm{F}=20-30 \%$ from median value).

- The average intensity of positive substorms has maximum at 13:00 UT and at 23:00 UT for negative storms, both with $I=275 \mathrm{nT}$.

For positive substorms, the intensity of absorption bays is generally lower than for negative ones with the same magnetic intensity. Also for positive substorms, the absorption bay is delayed relative to the magnetic field bay by about $1 \mathrm{~h}$, a time consistent with injected energetic electrons at midnight drifting eastwards under the actions of gradient and curvature drift. Absorption usually diminishes with decreasing 

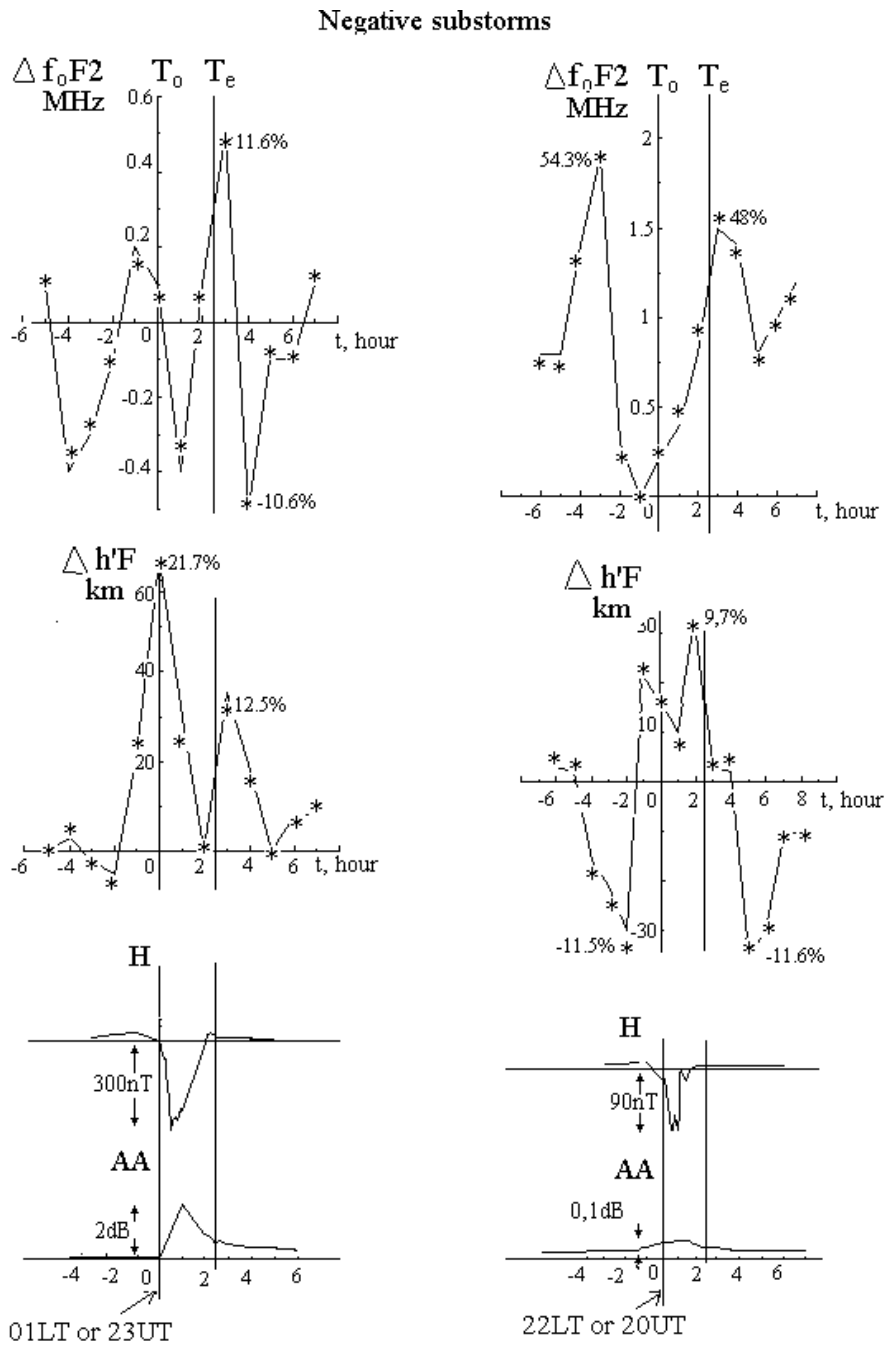

12. 08.1998

$\tau=2$ hours

20. 02.1999

Fig. 2. The variations of $\Delta f o \mathrm{~F} 2, \mathrm{MHz}$ and $\Delta h^{\prime} \mathrm{F}$, km (only solid lines) for two negative substorms, together with the corresponding variations of the $X$-component and absorption measured at the Sodankyla observatory. The vertical lines mark substorm onset, $T_{O}$, and the end of the substorm, $T_{e}$. Asterisks are $\delta f o \mathrm{~F} 2(\%)$ and $\delta h^{\prime} \mathrm{F}(\%)$ reduced to the maximum value.

latitude in the range $\Lambda=67.4^{\circ}-62.3^{\circ}$ for both positive and negative substorms. Variations of the magnetic field components $X, Y$ and $Z$ during substorm-time change little with latitude in the range $\Lambda=67.4^{\circ}-60.5^{\circ}$, i.e. the shape of the bays remains approximately constant and the amplitude diminishes only slightly from high to low latitudes.

\section{Analysis of the ionospheric parameters}

Most attention has been concentrated on the changes of two ionospheric parameters $f o \mathrm{~F} 2$ and $h^{\prime} \mathrm{F}$ during substorms. Variations of these hourly parameters relative to the monthly medians, namely $\Delta f o \mathrm{~F} 2$ and $\Delta h^{\prime} \mathrm{F}$, have been determined for $6 \mathrm{~h}$ before the time of onset, $T_{o}$, to $6 \mathrm{~h}$ after the end of the substorm $\left(T_{e}\right)$. Three approaches have been adopted. First data from a single station (Sodankyla) are used to determine the variations of $\Delta f o \mathrm{~F} 2$ and $\Delta h^{\prime} \mathrm{F}$ during negative and positive substorms. The second analysis addresses the variations of the ionospheric parameters with latitude using data from one chain of 5 stations. The third analysis examines the spatial and temporal effects using data from three chains of stations.

The Sodankyla data were considered for negative and positive substorms separately. The negative substorms selected are considered in four groups based on their duration, $(\tau)(\mathrm{Ta}-$ ble 1). These groups are (1) $\tau=1-1.5 \mathrm{~h}$ (7 substorms); (2) $\tau=2-2.5 \mathrm{~h}$, (15); (3) $\tau=3-3.5 \mathrm{~h}$, (3), and (4) $\tau=4-6 \mathrm{~h}$ (4). For the 12 positive storms only three groups were created - (1) $\tau=1-2 \mathrm{~h}$ (4 substorms); (2) $\tau=3-3.5 \mathrm{~h} \mathrm{(6),}$ and (3) $\tau=5-5.5 \mathrm{~h}$ (2). According to these data, the negative substorms of $\tau=2-2.5 \mathrm{~h}$ duration and the positive substorms of $\tau=3-3.5 \mathrm{~h}$ duration have the highest probability $(P=0.5)$. This analysis did not include any data from the winter months (November-February). This is because 


\section{Positive substorms}
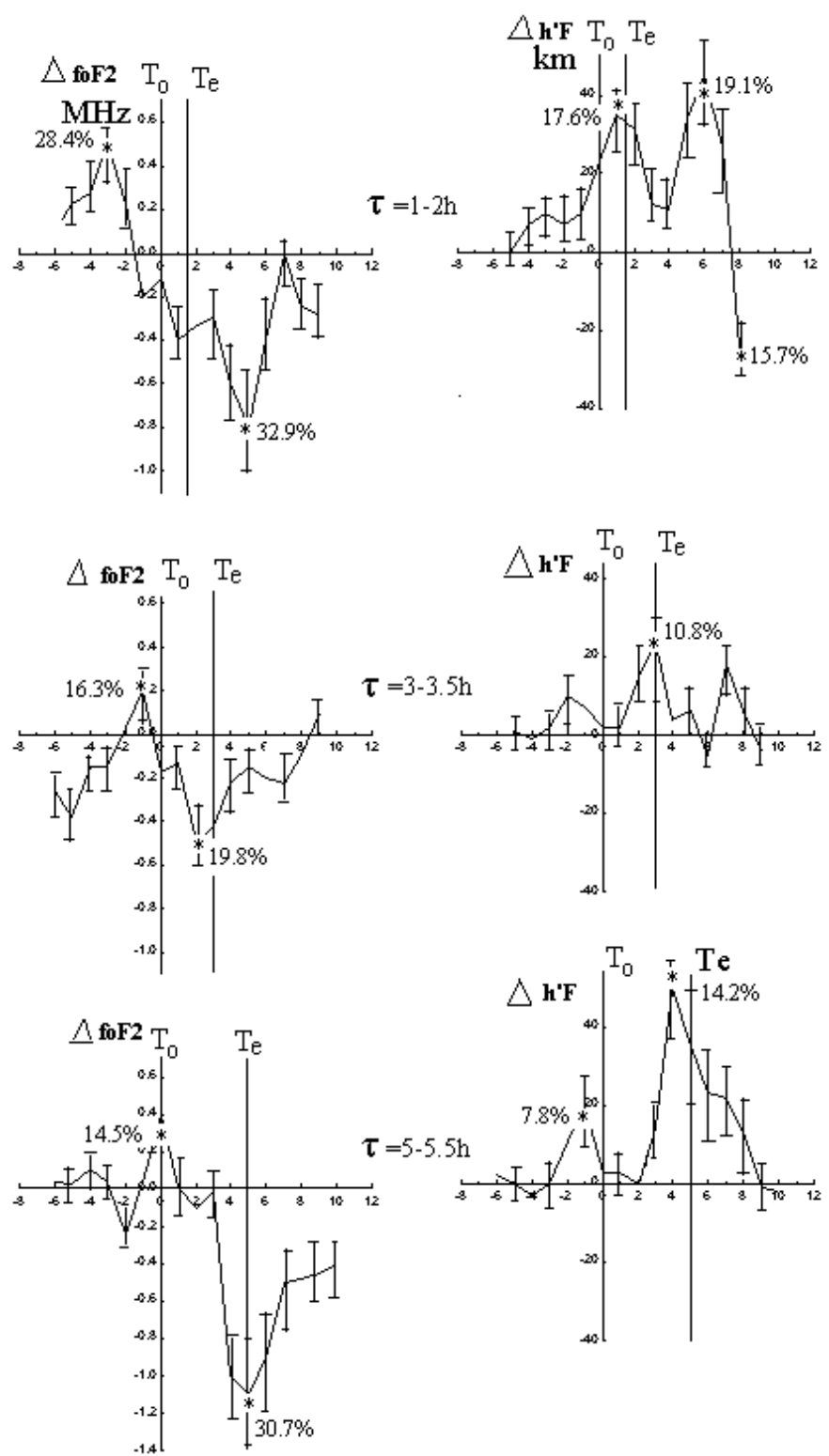

Fig. 3. The average variations of $\Delta f o \mathrm{~F} 2$ and $\Delta h^{\prime} \mathrm{F}$ separated by duration into 3 classes: $\tau=1-2 \mathrm{~h}, \tau=3-3.5 \mathrm{~h}$, and $\tau=5-5.5 \mathrm{~h}$. The vertical lines mark substorm onset, $T_{o}$ and the average end of the substorm, $T_{e}$. Asterisks are $\delta f o \mathrm{~F} 2(\%)$ and $\delta h^{\prime} \mathrm{F}(\%)$ values.

the data were largely absent owing to blackout or screening by sporadic-E.

The average variations of parameters $\Delta f o \mathrm{~F} 2$ and $\Delta h^{\prime} \mathrm{F}$ during negative substorms of the four duration groups are shown in Fig. 1. Vertical lines mark the onset time of the expansion, $T_{o}$, and $T_{e}$. From $6-8 \mathrm{~h}$ before $T_{o}$, the $\Delta f o \mathrm{~F} 2$ values increase up to maximum $2-3 \mathrm{~h}$ before $T_{o}$ for all four groups. Then up to $T_{o}$ there is a sharp decline in $\Delta f o \mathrm{~F} 2$ to a minimum near $T_{o}$, with a further rise taking place during the expansion phase. The second maximum occurs $<2 \mathrm{~h}$ after $T_{e}$. Thereafter, $\Delta f o \mathrm{~F} 2$ become more irregular. The existence of two maxima before $T_{o}$ and after $T_{e}$ and the minimum near $T_{o}$ is a clear substorm effect.

Changes in $\Delta h^{\prime} \mathrm{F}$ have a different character. There is a small minimum 3-4h before $T_{o}$, and a first maximum about $T_{o}$, in most cases. Then $\Delta h^{\prime} \mathrm{F}$ values drop to a minimum within the expansion phase and increase to the end of this phase again. The second maximum occurs near $T_{e}$, then $\Delta h^{\prime} \mathrm{F}$ falls to a second minimum 2-3 h after $T_{e}$.

Figure 2 gives the $\Delta f o \mathrm{~F} 2$ and $\Delta h^{\prime} \mathrm{F}$ values for two specific substorms that occurred on 12 August 1998 and on 20 February 1999; these are examples from the most probable class of substorm with $\tau=2-2.5 \mathrm{~h}$. These data demonstrate that individual substorm patterns of $\Delta f o \mathrm{~F} 2$ and $\Delta h^{\prime} \mathrm{F}$ conform to 


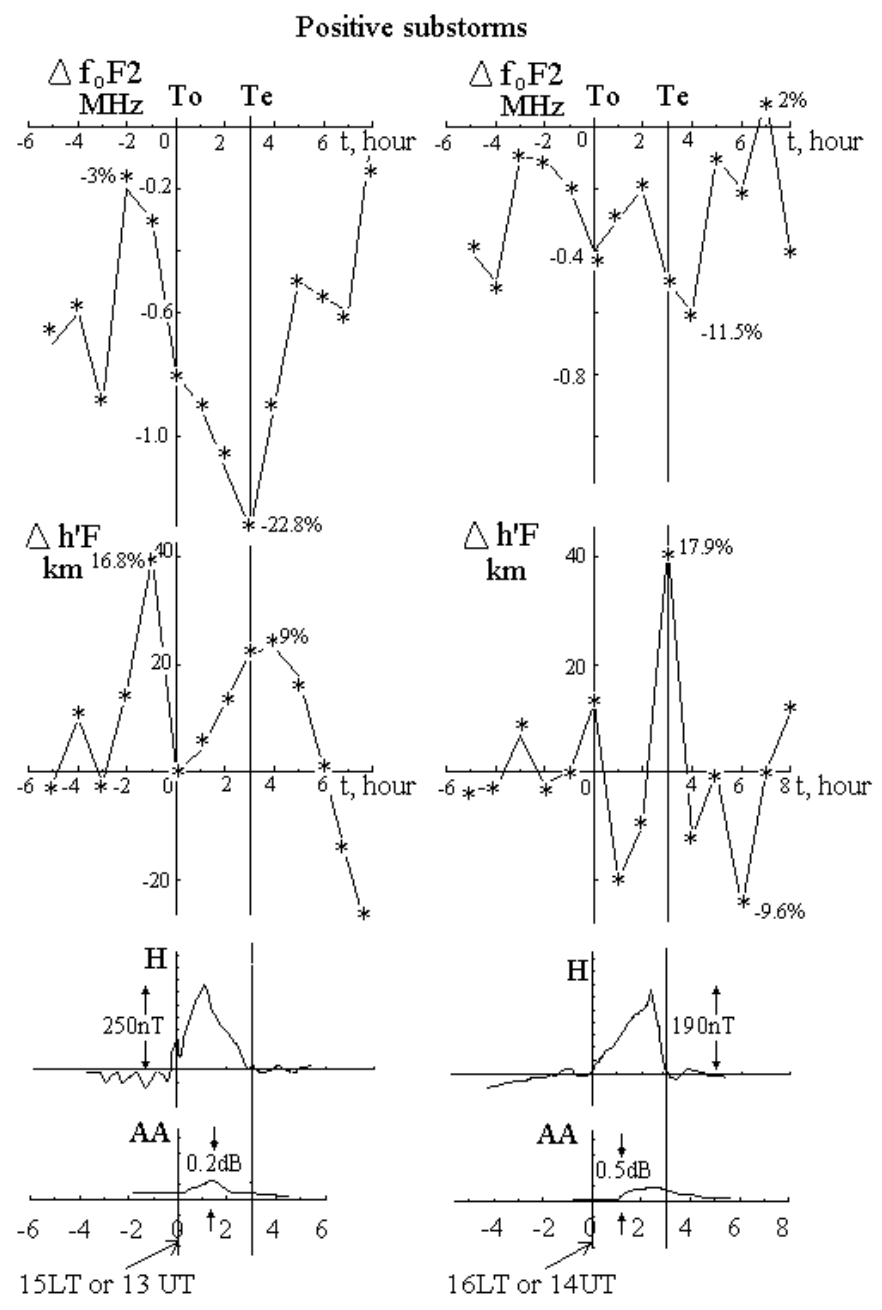

17.04.1998 $\tau=3$ hours 16.06 .1998

Fig. 4. The variations of $\Delta f o \mathrm{~F} 2, \mathrm{MHz}$ and $\Delta h^{\prime} \mathrm{F}, \mathrm{km}$ (only solid lines) for two positive substorms, together with the corresponding variations of the $X$-component and absorption measured at the Sodankyla observatory. The vertical lines mark substorm onset, $T_{o}$, and the end of the substorm, $T_{e}$. Asterisks are $\delta f o \mathrm{~F} 2(\%)$ and $\delta h^{\prime} \mathrm{F}(\%)$ reduced to the maximum value.

the general pattern shown in Fig. 1. The lower part of Fig. 2 shows the $X$-components of geomagnetic field variations and the riometer absorption curves from the Sodankyla observatory.

The average variations of parameters $\Delta f o \mathrm{~F} 2$ and $\Delta h^{\prime} \mathrm{F}$ during positive substorms separated by duration $\tau$ are shown in Fig. 3. They show some differences from the negative substorms illustrated in Figs. 1 and 2. Here, the timing of the maximum $\Delta f o \mathrm{~F} 2$ that occurs before $T_{o}$ depends on substorm duration; the longer the duration of the substorm, the closer the maximum occurs to $T_{o} . \Delta f o \mathrm{~F} 2$ reaches a minimum close to the end of the expansion phase, $T_{e}$. For the shortest duration substorms, the minimum $\Delta f o \mathrm{~F} 2$ is $2-3 \mathrm{~h}$ after $T_{e}$. All $\Delta f o \mathrm{~F} 2$ show signs of recovery $\sim 5$ hours after $T_{e}$.

There is a small maximum of $\Delta h^{\prime} \mathrm{F}$ before $T_{o}$, that occurs closer to $T_{o}$ if the substorm is longer. By far the most significant and consistent feature is a peak of $\Delta h^{\prime} \mathrm{F}$ close to $T_{e}$.
Figure 4 illustrates two positive substorms (for 17 April 1998 and 16 June 1998). The variations of $\Delta f o \mathrm{~F} 2$ and $\Delta h^{\prime} \mathrm{F}$ values of these substorms agree with the average curves presented in Fig. 3 for disturbances with duration of $\tau=$ $3-3.5 \mathrm{~h}$. The lower part of Fig. 4 shows the $X$-component of geomagnetic field variations and the riometer absorption curves from Sodankyla. Here there is a delay of the absorption bay onset by $1-1.5 \mathrm{~h}$ relative to $T_{o}$. No such delay is present for negative substorms (Fig. 2). As mentioned earlier, the delay can be attributed to the effects of energetic electrons injected near midnight, gradient and curvature drifting eastwards into the afternoon sector.

To determine the latitude variations of the parameter $\Delta f o \mathrm{~F} 2$ during substorms, data from a chain of stations comprising Kiruna, Lycksele, Uppsala, Warsaw and Sofia were examined. Much $\Delta h^{\prime} \mathrm{F}$ data were absent from these observatories and, therefore, its latitude response could not be deter- 


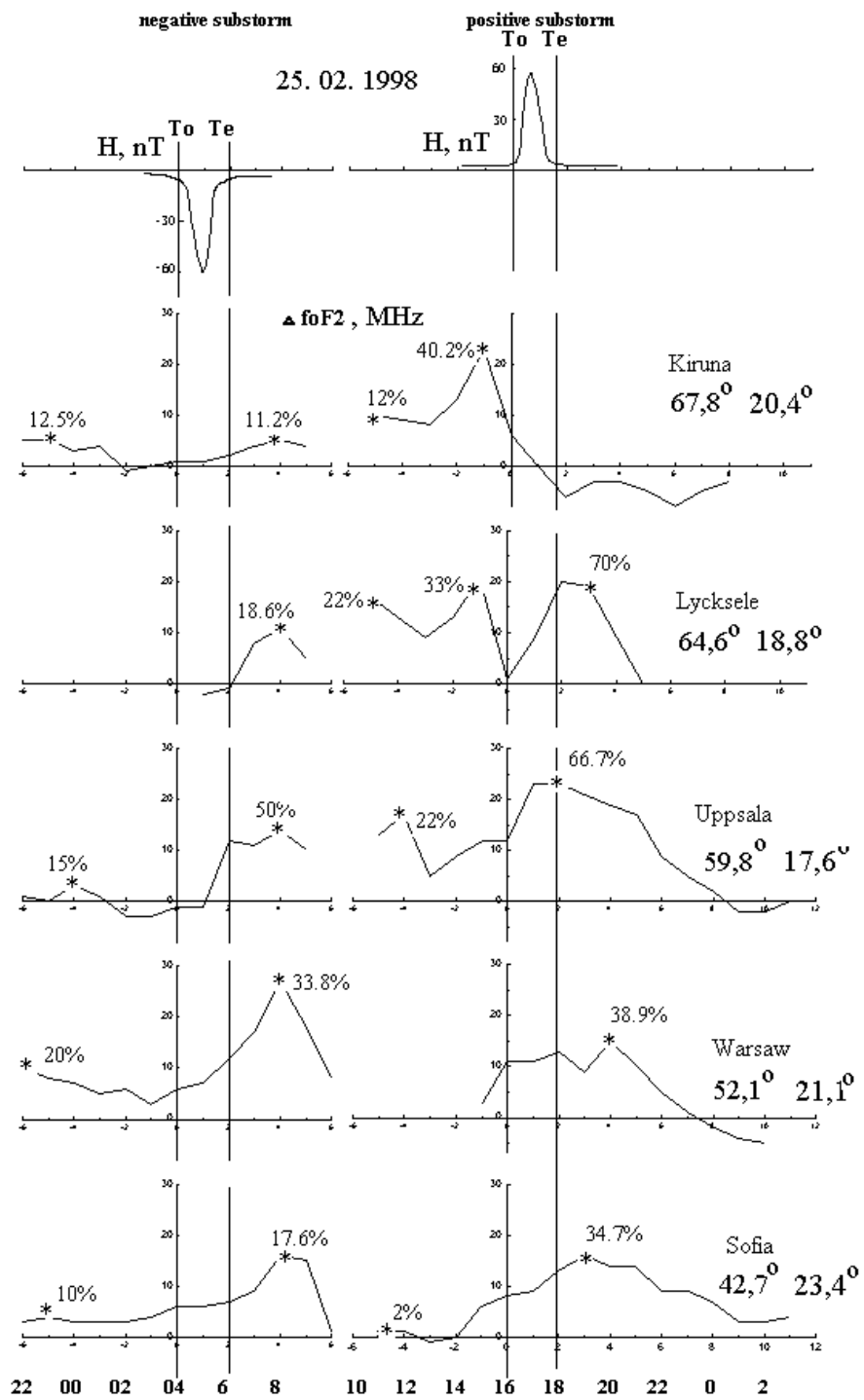

Fig. 5. The variations of the $X$-component magnetometer data from Sodankyla observatory for a positive and negative substorm that occurred on 25 February 1998, together with variations of $\Delta f o \mathrm{~F} 2$ from Kiruna, Lycksele, Uppsala, Warsaw and Sofia $(\mathrm{LT}=\mathrm{UT}+2)$. The vertical lines mark substorm onset, $T_{o}$, and the end of the substorm, $T_{e}$. Asterisks are $\delta f o \mathrm{~F} 2(\%)$ values.

mined. Two positive and three negative substorms for February 1999 have been analysed in detail.

On 25 February 1999, two isolated substorms took place and are illustrated in Fig. 5. $T_{o}$ of the negative substorm was at 04:00 UT (06:00 LT) with $T_{e}$ at 06:00 UT (08:00 LT), thus its duration, $\tau$, was $2 \mathrm{~h}$. The intensity $I$ was $-60 \mathrm{nT}$. The second substorm was positive with duration $\tau=1.5 \mathrm{~h}$ and intensity $I=+60 \mathrm{nT}$, with $T_{o}=16: 00 \mathrm{UT}(18: 00 \mathrm{LT})$ and $T_{e}$ $=18: 00$ UT (20:00 LT). Data in Fig. 5 are typical; they describe the general regularities obtained by the five substorms studied. Basic results are as follows:

- Although the intensities of the substorms are small, $\Delta f o \mathrm{~F} 2$ variations are observed at all stations considered from $6 \mathrm{~h}$ before $T_{o}$ and $\sim 8 \mathrm{~h}$ after $T_{e}$.

The $\Delta f o \mathrm{~F} 2$ variations for the negative substorm differ from the positive substorm most at high latitudes $\left(\Lambda>50^{\circ}\right)$. At middle and low latitudes $\left(\Lambda<50^{\circ}\right)$ differences are small. For the northernmost ionospheric station, Kiruna, the $\Delta f o \mathrm{~F} 2$ variations repeat the average statistical regularities of Sodankyla presented in Fig. 1 for $\tau=2-2.5$ h, and Fig. 3 for $\tau=1-2 \mathrm{~h}$. This is hardly surprising given that the stations are close to each other but does confirm again the reliability of the averaged data. At high latitudes $\left(>60^{\circ}\right)$ for negative and positive substorms, $\Delta f o \mathrm{~F} 2$ rises and falls, occuring both $1-3 \mathrm{~h}$ before $T_{o}$ and $1-3 \mathrm{~h}$ after $T_{e}$.

- At middle and low latitudes ionospheric responses to negative and positive substorms are similar to each other. A small rise in $\Delta f o \mathrm{~F} 2$ starts before $T_{o}$, and reaches a maximum near or slightly after $T_{e}$ before falling steadily towards the pre-substorm values.

- The $\Delta f o \mathrm{~F} 2$ values reach their maximum deviation $(\sim 2-$ 


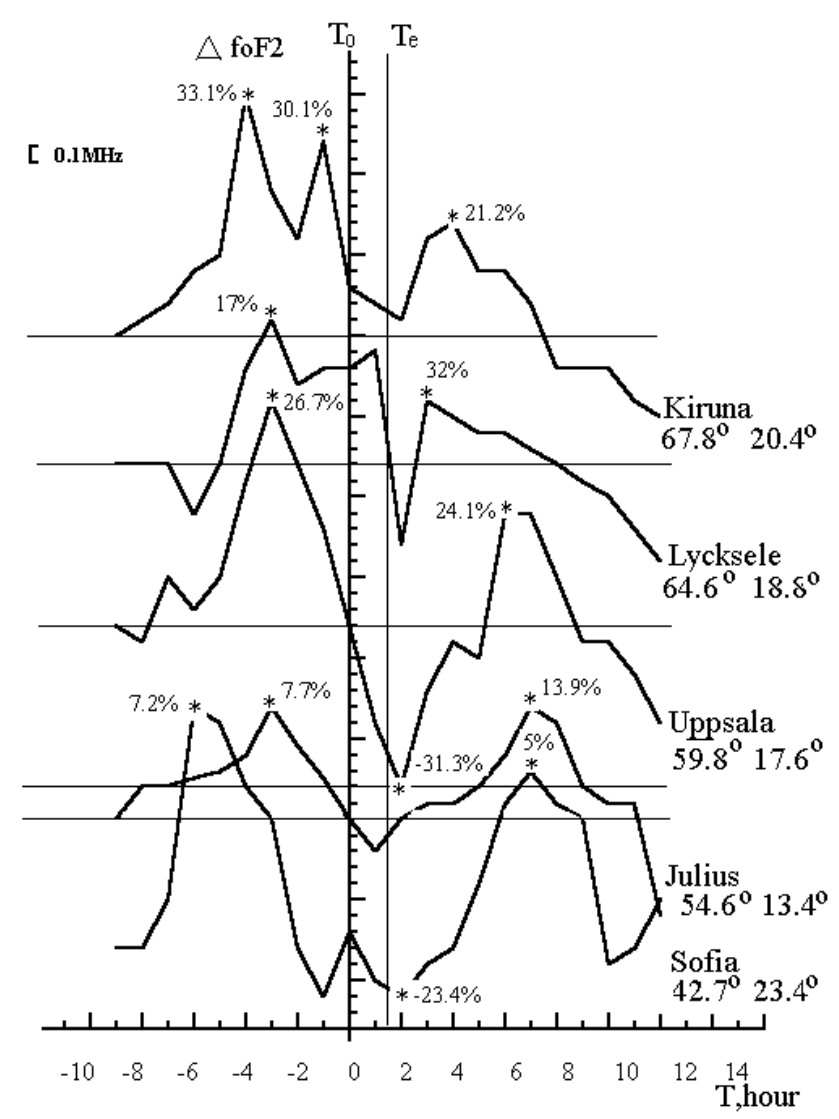

Fig. 6. The variations of $\Delta f o \mathrm{~F} 2$ values for the negative substorm that occurred on 27 March $1999\left(T_{o}=22: 00 \mathrm{UT}\right.$ or 00:00 LT, $I=$ $-110 \mathrm{nT}, \tau=1.5 \mathrm{~h}$ ) through the first (northern) longitudinal chain of stations of the IDCE, LT $=\mathrm{UT}+2$. The vertical lines mark substorm onset, $T_{o}$, and the end of the substorm, $T_{e}$. Asterisks are $\delta f o \mathrm{~F} 2(\%)$ values.

$3 \mathrm{MHz}$ ) at the latitude $\Lambda=55^{\circ}$. Moreover, at high latitudes, the $\Delta f o \mathrm{~F} 2$ values can be both positive and negative but at middle and low latitudes they are all positive.

To determine the spatial and temporal effects, individual substorms from March 1999 (see Table 1) were examined. The data from the network of ionosonde stations are considered in three groups. The first includes 7 stations over an extended latitude range but within longitudinal interval $\pm 5^{\circ}$, stretching from Kiruna $\left(67.8^{\circ} \mathrm{N}\right)$, through Lycksele, Uppsala, Juliusruh, Warsaw, Pruhonice to Sofia $\left(42.7^{\circ} \mathrm{N}\right)$. A second latitude chain, but at lower latitudes and $\sim 15^{\circ}$ further east includes Slough $\left(51.5^{\circ} \mathrm{N}\right)$, Lannion, Tortosa and El Arenosillo $\left(37.1^{\circ} \mathrm{N}\right)$. A third chain were at a fixed latitude $\left( \pm 3^{\circ}\right)$ and extended in longitude from Uppsala $\left(17.6^{\circ} \mathrm{E}\right)$, through St. Petersburg, Sverdlovsk, Novosibirsk to Podkamennaya $\left(90^{\circ} \mathrm{E}\right)$. In addition, data from Salekhard $\left(66.5^{\circ}\right.$; $\left.66.5^{\circ}\right)$ and Taoywan $\left(25^{\circ} ; 121^{\circ}\right)$ were examined. Occasionally, data from a few stations were not available. These networks cover most of Europe and western Asia.

The $\Delta f o \mathrm{~F} 2$ variations for two illustrative substorms a negative one on 27 March $1999\left(T_{o}=22: 00 \mathrm{UT}, I=\right.$

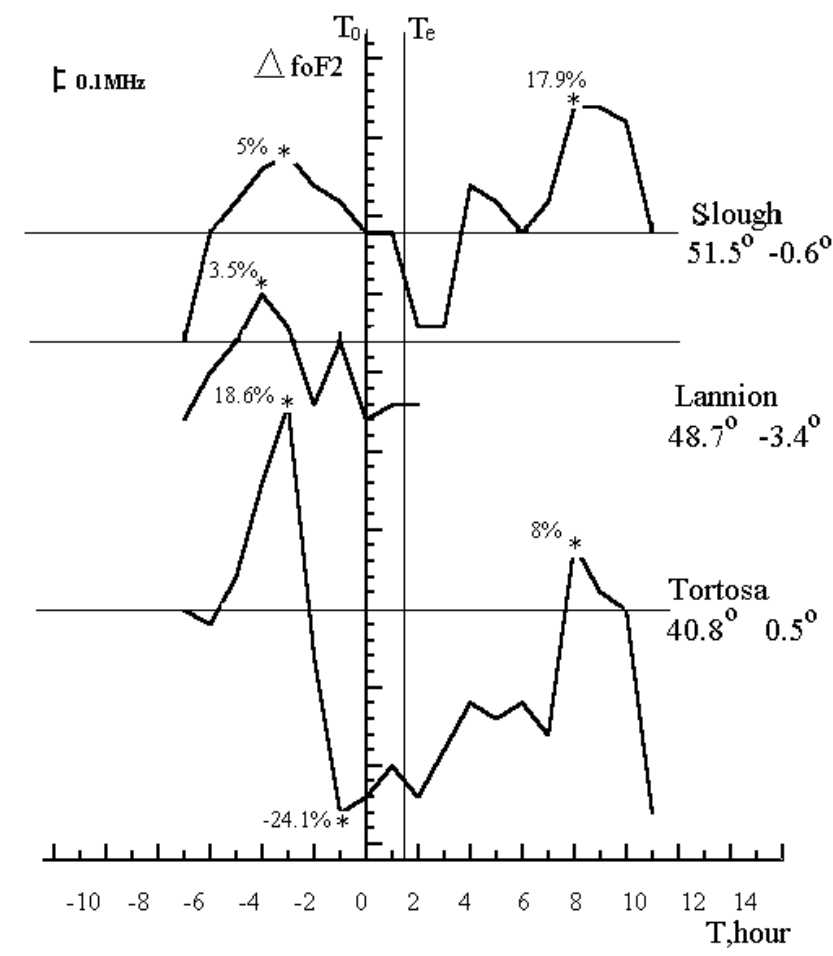

Fig. 7. The variations of $\Delta f o \mathrm{~F} 2$ values for the negative substorm that occurred on 27 March $1999\left(T_{o}=22: 00\right.$ UT or 22:00 LT, $I=$ $-110 \mathrm{nT}, \tau=1.5 \mathrm{~h}$ ) through the second (southern) longitudinal chain of stations of the IDCE, LT = UT. The vertical lines mark substorm onset, $T_{o}$, and the end of the substorm, $T_{e}$. Asterisks are $\delta f o \mathrm{~F} 2(\%)$ values.

$-110 \mathrm{nT}$ and $\tau=1.5 \mathrm{~h}$ ), and a positive one on 5 March 1999 ( $T_{o}=16: 00 \mathrm{UT}, I=+220 \mathrm{nT}, \tau=1.5 \mathrm{~h}$ ) are presented in Figs. 6-8, and Figs. 9-11, respectively for the three chains of stations. The key results are summarised below as follows.

The character of the $\Delta f o \mathrm{~F} 2$ variations with latitude (Fig. 6-10) during negative and positive substorms is approximately the same. The important features are the increase in $\Delta f o \mathrm{~F} 26-8 \mathrm{~h}$ before $T_{o}$, then dropping to a minimum near $T_{e}$, thereafter increasing again to a maximum $\Delta f o \mathrm{~F} 2 \sim 4-5 \mathrm{~h}$ later. This illustrates the large latitudinal spread of substorm effects.

Substorm effects are clearer and more pronounced for negative substorms than for positive ones, even though the intensity of the positive substorm is twice that of the negative one. Also for positive substorms, $\Delta f o \mathrm{~F} 2$ values are mainly negative at latitudes $>50^{\circ}$. At low latitudes $\left(<50^{\circ}\right)$ they are both negative and positive (Figs. 9 and 10).

Analysis of all the March substorms reveals that at a single station some differences in the $\Delta f o \mathrm{~F} 2$ variations which occur from one substorm to another are probably associated with their different intensities, $T_{o}$ and $\tau$ values, and whether the substorm is positive or negative. However, for latitudes $<50^{\circ}$, the $\Delta f o \mathrm{~F} 2$ variations are remarkably similar and stable, both between themselves for a single substorm and for substorms of different intensity and sign (e.g. Figs. 7 and 


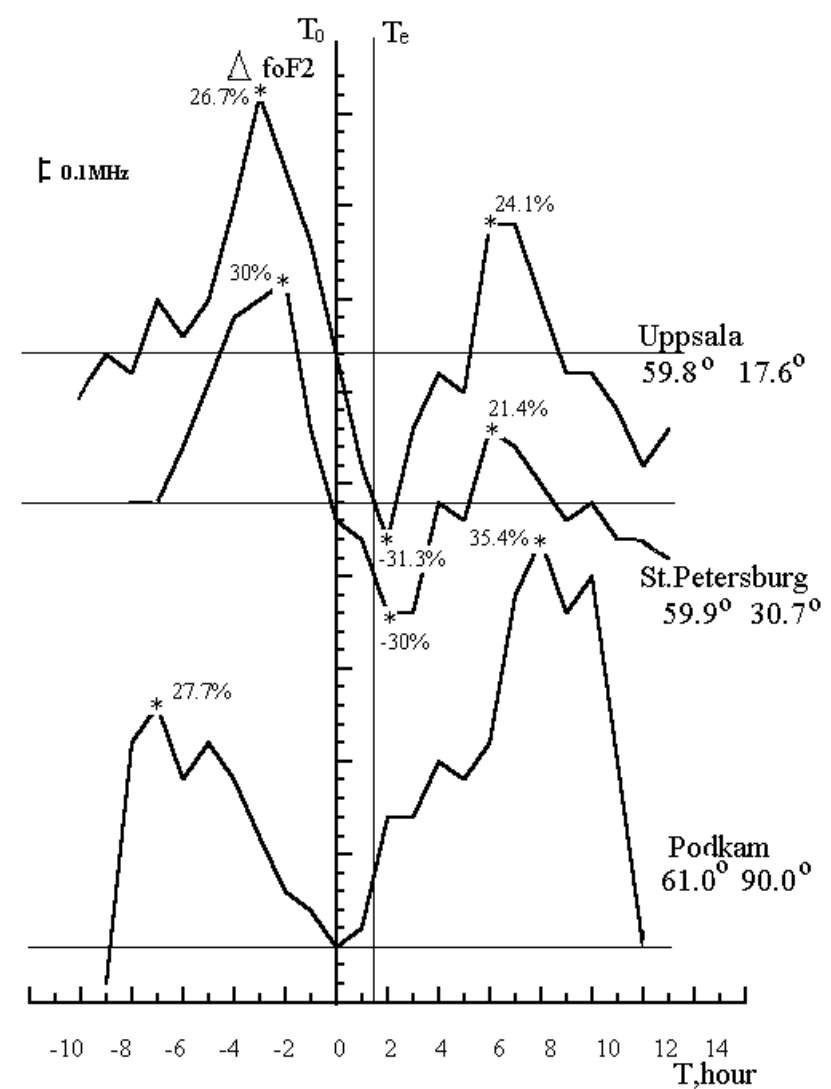

Fig. 8. The variations of $\Delta f o \mathrm{~F} 2$ values for the negative substorm that occurred on 27 March $1999\left(T_{O}=22: 00 \mathrm{UT}, I=-110 \mathrm{nT}\right.$, $\tau=1.5 \mathrm{~h}$ ) through the latitudinal chain of stations of the IDCE, Upp.: $\mathrm{LT}=\mathrm{UT}+2$, St. P.: $\mathrm{LT}=\mathrm{UT}+3$, Pod.: $\mathrm{LT}=\mathrm{UT}+8$. The vertical lines mark substorm onset, $T_{o}$, and the end of the substorm, $T_{e}$. Asterisks are $\delta f_{o} \mathrm{~F} 2(\%)$ values.

10). Therefore, the latitude $\Lambda \approx 50^{\circ}$ can be considered as a boundary between the less stable area to the north and a more stable area to the south of $50^{\circ} \mathrm{N}$. Hence, these differences with latitude may be important for developing accurate forecasting of substorm effects.

The variations of $\Delta f o \mathrm{~F} 2$ with longitude are remarkably small (Figs. 8 and 11), illustrating, that the effects can extend over $70^{\circ}$ in longitude. The $\Delta f o \mathrm{~F} 2$ variations from Salekhard are similar to the variations on the longitude chain but results from Taoywan are very different in character. This may be due to the fact that the substorm effects do not extend this far east, or the tilted auroral oval with respect to magnetic local time means that the station lies too far from oval at the time of the substorm for effects to be detected.

Data of the IMAGE magnetometer network were used in addition to analysis of the March substorms. These data allow one to determine a location of electrojet during any substorm. The location of the electrojet center can be defined from the examination of the peculiarities in the behavior of the $X$ and $Z$ magnetic components. Maximal negative values of the $X$ component and $Z=0$ (reversal of the $Z$ component

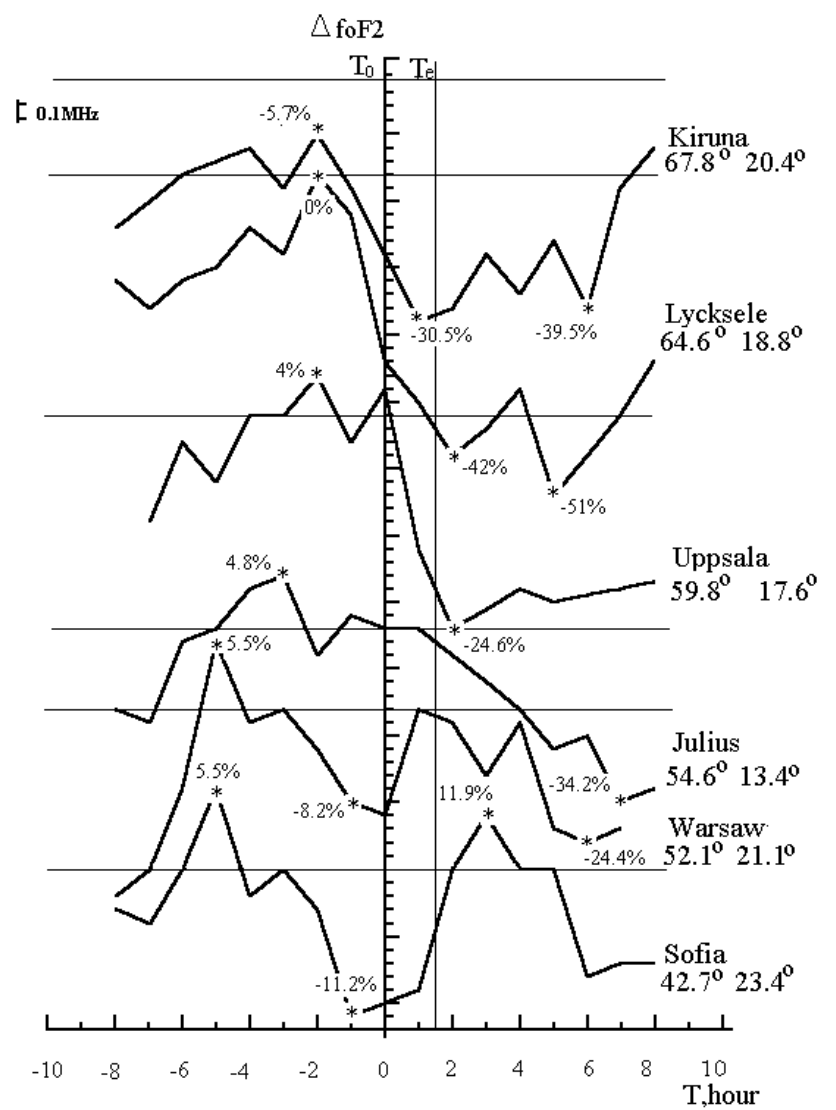

Fig. 9. The variations of $\Delta f o \mathrm{~F} 2$ values for the positive substorm that occurred on 05 March $1999\left(T_{o}=16: 00\right.$ UT or 18:00 LT, $I=$ $+220 \mathrm{nT}, \tau=1.5 \mathrm{~h}$ ) through the first (northern) longitudinal chain of stations of the IDCE, LT $=\mathrm{UT}+2$. The vertical lines mark substorm onset, $T_{o}$, and the end of the substorm, $T_{e}$. Asterisks are $\delta f o \mathrm{~F} 2(\%)$ values.

from positive to negative values) are indicative for the center's westward electrojet location. Results of studies for the events considered here are as follows.

- The westward electrojet was centered at the invariant latitude $\Phi_{L}=65^{\circ}$ (or geographic latitude $\varphi=69^{\circ}$ ) for the substorm event on 27 March 1999. Southward from this latitude, the direction of electrojet remains westward but its intensity decreases.

- The westward electrojet has its maximal value at the invariant latitude $\Phi_{L}=72^{\circ}$ (or geographic latitude $\varphi=76^{\circ}$ ) for the substorm event on 5 March 1999. However, to south from this latitude its direction becomes eastward. There are positive values of the $X$ component on the contrary to the event on 27 March 1999.

It is worth mentioning that for examined substorm events, the onsets of auroral activation from the IMAGE data and from the $A E$-index, characterized by the global auroral activity, are coincided. Therefore, the auroral substorms started at the meridian of the IMAGE magnetometer network. 


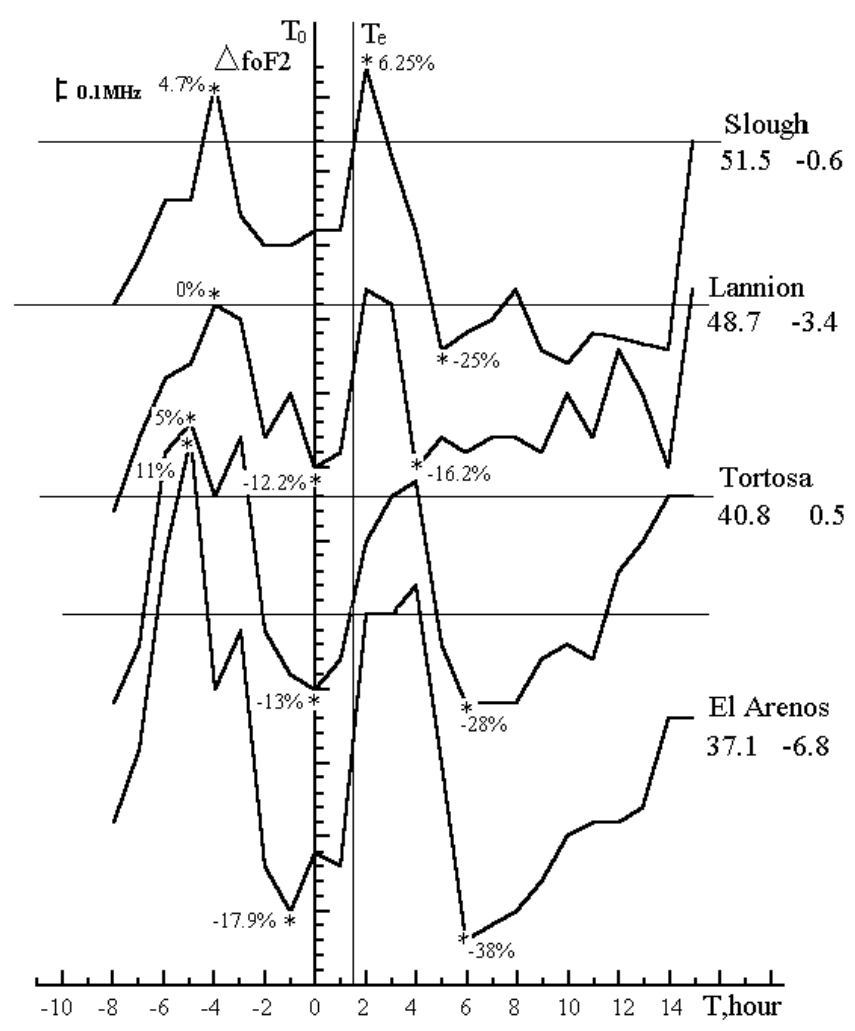

Fig. 10. The variations of $\Delta f o \mathrm{~F} 2$ values for the positive substorm that occurred on 05 March $1999\left(T_{O}=16: 00 \mathrm{UT}\right.$ or 16:00 LT, $I=$ $+220 \mathrm{nT}, \tau=1.5 \mathrm{~h}$ ) through the second (southern) longitudinal chain of stations of the IDCE, LT = UT. The vertical lines mark substorm onset, $T_{o}$, and the end of the substorm, $T_{e}$. Asterisks are $\delta f o \mathrm{~F} 2(\%)$ values.

\section{Possible physical mechanism for the explanation of observations}

Here, the physical mechanisms that may cause the observed features are briefly discussed. One of the main results is that positive $\Delta f o \mathrm{~F} 2$ variations are observed for many hours before substorm onset. This is difficult to understand as the time between a southward turning after a period of geomagnetic quiescence and a substorm is typically $1-2 \mathrm{~h}$. However, it must be recalled that $\Delta f o \mathrm{~F} 2$ variations are determined by subtracting the median ionospheric conditions, and this may not be appropriate for such quiet conditions. Future studies will assess the validity of using medians.

The probability of substorms with about $5 \mathrm{~h}$ between any two separated substorms is low and there are the maximum 20 "clear" isolated substorms in a year (Borovsky et al., 1993). In our case we have 41 isolated substorms in the year. Therefore, these observations may have some residuals effects from previous disturbances. Development of isolated substorms could be controlled by the behaviour of the $\varepsilon$ parameter (Akasofu, 1968) which begins to grow some hours before $T_{o}$ (Freeman et al., 1993; Kerns and Gussenhoven,

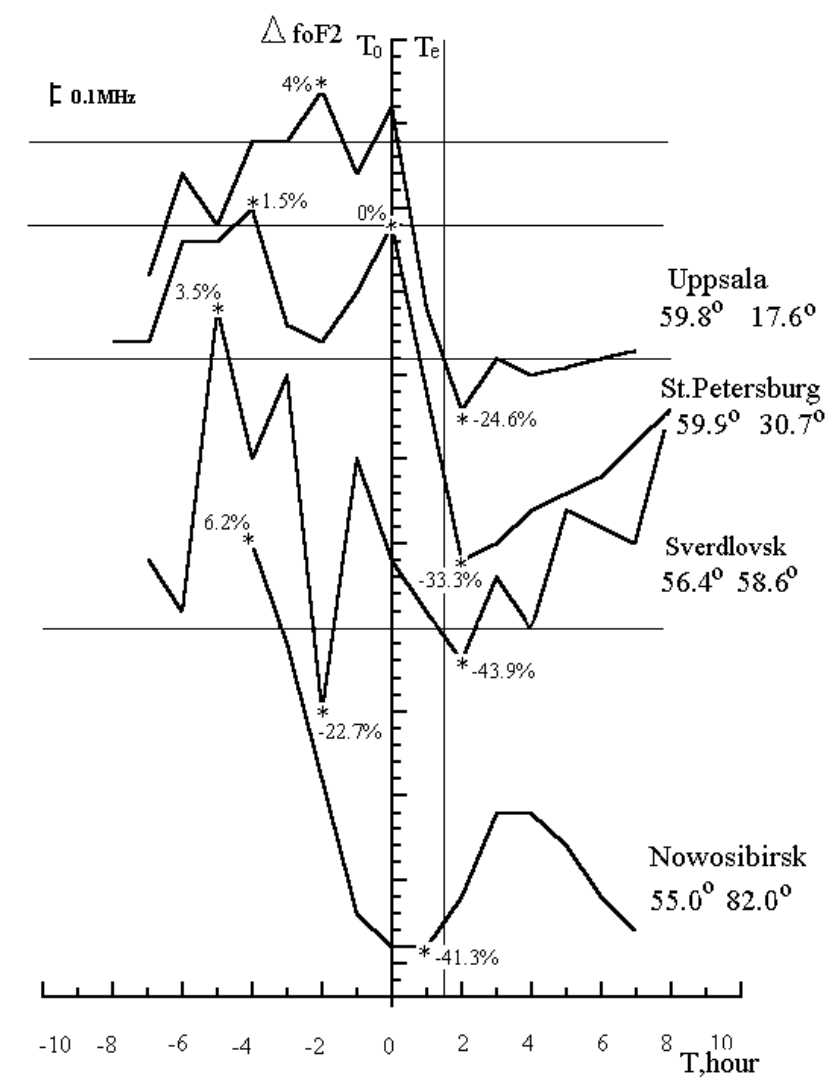

Fig. 11. The variations of $\Delta f o \mathrm{~F} 2$ values for the positive substorm that occurred on 05 March $1999\left(T_{o}=16: 00 \mathrm{UT}, I=+220 \mathrm{nT}\right.$, $\tau=1.5 \mathrm{~h}$ ) through the latitudinal chain of stations of the IDCE, Upp.: $\mathrm{LT}=\mathrm{UT}+2$, St. P.: $\mathrm{LT}=\mathrm{UT}+3$, Sv.: $\mathrm{LT}=\mathrm{UT}+6$, Now.: $\mathrm{LT}=\mathrm{UT}+7$. The vertical lines mark substorm onset, $T_{o}$, and the end of the substorm, $T_{e}$. Asterisks are $\delta f o \mathrm{~F} 2(\%)$ values.

1990) but analysis of the IMF data for these substorms has not yet been undertaken.

The observed variations of $\Delta f o \mathrm{~F} 2$ may be associated with the effects of the energy and momentum transfer from the solar wind to the magnetosphere and ionosphere. In particular, increased fluxes of soft particle precipitation in the midday cusp, and Joule heating may affect thermospheric composition and circulation. The changes in the ratio $[0] /[\mathrm{N} 2]$ can be transported to lower latitudes and across the polar cap by the neutral wind (Danilov and Belik, 1991). This effect can precede the onset of a substorm by several hours. However, more observations will be required to determine the physical processes responsible for the pre-onset disturbances. After $T_{o}$, the variations of $\Delta f o \mathrm{~F} 2$ and $\Delta h^{\prime} \mathrm{F}$ obey the traditional transfer scheme corresponding to the tail modification, auroral precipitation, heating, TIDs propagation, ring current and so on, as described by several authors (see, for example, Fuller-Rowell et al., 1994). 


\section{Conclusions}

Using the data from 19 ionospheric and some geomagnetic observatories, the spatial variations of the height and maximum plasma frequency of the F2-layer have been determined for 41 isolated substorm intervals. The observatories extend all over Europe and western Asia. The substorms were selected because they had a sharp onset, lasted a few hours and occurred during a several hour period of geomagnetic quiet both before and after the study interval. The substorms had intensities of $I \geq 50 \mathrm{nT}$. Very intense substorms $(I>500 \mathrm{nT})$ are not included in the analysis, due to the effects of a strong absorption and sporadic Es-layers which prevent F-region observations. The key findings are as follows:

1. Substorm effects in the ionosphere occur simultaneously ( $1 \mathrm{~h}$ resolution) almost all over Europe and the western part of Asia.

2. Negative substorms. (i) The $\Delta f o \mathrm{~F} 2$ values increase $>6 \mathrm{~h}$ before substorm onset, $T_{o}$, with a maximum 2$3 \mathrm{~h}$ before $T_{o} . \Delta f o \mathrm{~F} 2$ falls during the expansion phase which is then followed by a second maximum $1-2 \mathrm{~h}$ after the end of the expansion phase. (ii) The $\Delta h^{\prime} \mathrm{F}$ values $3-4 \mathrm{~h}$ before $T_{o}$ have a little minimum but then increase to a maximum at $T_{o}$. There is a second maximum at the end of the expansion phase.

3. Positive substorms. The timing of the first maximum of the $\Delta f o \mathrm{~F} 2$ and $\Delta h^{\prime} \mathrm{F}$ values depends on the substorm length - if it is longer, the peak is closer to $T_{o}$.

4. The values of the ionospheric parameters $\Delta f o \mathrm{~F} 2$ and $\Delta h^{\prime} \mathrm{F}$ during a substorm-time can reach the sizes $|\Delta f o \mathrm{~F} 2|=2-3 \mathrm{MHz}(\delta f o \mathrm{~F} 2=50-70 \%$ from median value $)$ and $\left|\Delta h^{\prime} \mathrm{F}\right|=50-70 \mathrm{~km}\left(\delta h^{\prime} \mathrm{F}=20-30 \%\right.$ from median value). The additional final goal is to find the physical mechanisms of the mentioned effect from the point of view of the solar-magnetospheric-ionospheric coupling.

5. The variations of $\Delta f o \mathrm{~F} 2$ and $\Delta h^{\prime} \mathrm{F}$ can affect significantly radio-wave propagation via the ionosphere and explain the MUF variations obtained early on the HF paths, but the regular pattern of occurrence with respect to the time of the expansion phase onset offers an excellent possibility to improve short-term forecasting of radio-wave propagation conditions. Furthermore, we are going to reveal some methods and algorithms of forecasting the onset of the substorm expansion phase.
Acknowledgements. The authors wish to thank colleagues from Finland, Kyoto WDC-C2 ( $A E$-indexes) and the IDCE for providing their data through the Internet. This work was supported by funding from the grant EST.CLG 975263.

Topical Editor M. Lester thanks two referees for their help in evaluating this paper.

\section{References}

Akasofu, S.-I.: Polar and magnetospheric substorms, Dordrecht, D. Reidel, 137p., 1968.

Blagoveshchensky, D. V. and Borisova T. D.: Substorm effects of ionosphere and HF propagation, Radio Sci, 35, 5, 1165-1171, 2000.

Blagoveshchensky, D. V., Egorova, L. V., and Lukashkin, V. M.: High-latitude ionospheric phenomena diagnostics by highfrequency radio wave propagation observations, Radio Sci., 27, 2, 267-274, 1992.

Blagoveshchensky, D. V., Borisova, T. D., and Egorova, L. V.: Preand after-substorm situations in the ionosphere and decameter radio wave propagation, Geomagn. Aeron., 96, 4, 125-134, 1996.

Borovsky, J. E., Wemzek R. J., and Belian, R. D.: The occurrence rate of magnetospheric substorms, J. Geophys. Res., 98, A3, 3807-3813, 1993.

Danilov, A. D. and Belik, L. D.: Thermosphere-ionosphere coupling during ionospheric storms (review), Geomagn. Aeron., 31, 2, 209-221, 1991.

Freeman, M. P., Farrugia, C. J., Burlaga, L. F., et al.: The interaction of a magnetic cloud with the Earth: Ionospheric convection in the northern and southern hemispheres for a wide range of quasisteady interplanetary magnetic field conditions, J. Geophys. Res., 98, A5, 7633-7655, 1993.

Fuller-Rowell, T. J., Codrescu, M. V., Moffett, R. J., and Quegan, S.: Response of the thermosphere and ionosphere to geomagnetic storms, J. Geophys. Res., 99, 3893-3914, 1994.

Kerns, K. J. and Gussenhoven, M. S.: Solar wind conditions for a quiet magnetosphere, J. Geophys. Res., 95, A6, 20 867-20875, 1990.

Lui, A. T. Y.: A synthesis of magnetospheric substorm models, J. Geophys. Res., 96, 1849-1856, 1991.

Piggott, W. R. and Rawer, K.: U.R.S.I handbook of ionogram interpretation and reduction, UAG-report 23 A, National Geophysical Data Center, Boulder, U.S.A., 1978.

Stanislavska, I., Gulyaeva, T. L., and Hanbaba, R.: Ionospheric Despatch Centre in Europe (IDCE), Proceedings of the 2nd COST 251 Workshop "Algorithms and Models for COST 251 Final Product", 30-31 March 1998, Side, Turkey. CLRC RAL, Chilton, Didcot, UK, 27-30, 1998.

Troshichev, 0. A., Andrezen, V. G, Vennerstrom, S., and FriisChristensen, E.: Magnetic activity in the polar cap - a new index, Planet. Space Sci., 36, 1095-1102, 1988. 